\title{
Staged Alkali and Hydrogen Peroxide Treatment of Poplar Chemi-Mechanical Pulp
}

\author{
Yuqian Guo, ${ }^{\mathrm{a}}$ Zhongjian Tian, ${ }^{\mathrm{a}}$ Xingxiang Ji, ${ }^{\mathrm{a}, *}$ Gaojin Lyu, ${ }^{\mathrm{a}} \mathrm{Jiachuan}$ Chen, ${ }^{\mathrm{a}}$ Guihua \\ Yang, ${ }^{a, *}$ and Lucian A. Lucia ${ }^{\mathrm{a}, \mathrm{b}}$
}

\begin{abstract}
In order to improve the physical properties and brightness of poplar chemimechanical pulp, a new staged alkali and hydrogen peroxide treatment method was proposed and applied. Wood chips were impregnated and swelled with an alkali solution and then treated with a hydrogen peroxide bleaching liquor. A thorough evaluation and comparison of the physical properties and brightness of the pulps that underwent different treatment methods was conducted. The results showed that when the pulp was treated with an alkali and hydrogen peroxide treatment method with an alkali dosage of $6 \%$ and a hydrogen peroxide dosage of $6 \%$, the tear index was $3.64 \mathrm{mN} \cdot \mathrm{m}^{2} / \mathrm{g}$, the tensile strength was $3.61 \mathrm{kN} / \mathrm{m}$, and the pulp brightness was $67.1 \%$ (ISO). The obtained physical properties and brightness of the alkali and hydrogen peroxide method treated pulp were greater than the traditional alkaline hydrogen peroxide method values, as well as the values of any other single treatment methods.
\end{abstract}

Keywords: Mechanical pulp; Alkaline hydrogen peroxide pretreatment; Physical properties; Brightness

Contact information: a: State Key Laboratory of Bio-based Materials and Green Papermaking, Qilu University of Technology (Shandong Academy of Sciences), 3501 Daxue Road, Jinan 250353, China; b: North Carolina State University, Department of Forest Biomaterials, Raleigh, NC 29675-8005, USA;

*Corresponding author: xxjt78@163.com; ygh2626@126.com

\section{INTRODUCTION}

Chemi-mechanical pulp is widely utilized in the production of various papers and paperboards due to its excellent fiber properties, such as high opacity, high bulk, high yield, and outstanding printing properties (Khakifirooz et al. 2013; Rainey and Covey 2016; Huang et al. 2017). For instance, newsprint could be produced from chemi-mechanical pulp, due to its high opacity and lower brightness requirements (Barimani et al. 2014). Good absorbent and high bulk properties makes it a good source for household paper (Chang et al. 2018). In addition, high-grade coated paper can also be produced by replacing part of the chemical pulp with chemi-mechanical pulp. Therefore, the treatment process for forming a wide range of characteristics from chemi-mechanical pulp fibers is very important. Moreover, selecting inexpensive chemicals and a suitable treatment method also improves the reaction efficiency at the treatment stage. It remains a challenge to reach an optimum efficiency with a shorter reaction time and lower chemical dosages. As a result, an effective chemical treatment is required to swell the wood chips, enhance the bonding strength between the fibers, and improve the physical strength and optical properties of the fibers (Lei et al. 2013).

Currently, various bleaching chemicals, such as hydrogen peroxide, sodium dithionite, sulfite, peracetic acid, sodium borohydride, etc., have primarily been used for industrial pulping purposes (Suess 2009, 2010; Nguyen 2011). Among these bleaching 
chemicals, sodium borohydride and peracetic acid are expensive and not conducive to reducing manufacturing costs (El Shafie et al. 2009; Istek and Gonteki 2009). In addition, sodium dithionite solutions are unstable in the air and easily react with metals to form sulfides, which are corrosive (Narvestad et al. 2013). Sodium sulfite was first used in the mechanical pulp bleaching process to prevent the pulp from darkening in the refining process. However, it had greater performance when sulfonating wood chips to improve the strength properties of chemi-mechanical pulp (Jurd 1964). Hydrogen peroxide is widely available due to its conspicuous bleaching efficiency and environmental friendliness (Bajpai 2012). Therefore, in newer bleaching technologies, an alkaline hydrogen peroxide treatment is widely applied, since it not only enhances the physical strength of the chemimechanical pulp, it also improves the optical properties of the fibers, which helps meet the requirements of various paper products. During an alkaline hydrogen peroxide treatment, alkali plays a crucial role by swelling the wood chips, softening the fibers, and improving the strength properties of the paper. An alkali treatment primarily removes a portion of the hemicellulose and lignin content. It also cause swelling in the fine cellulose structures, and thus weakens the hydrogen bonds between the fibers, which increases the porosity of the cell wall. Finally, these treatments enhance the reaction area on the fibers accessible to the alkali solution (Cuissinat et al. 2008; Le Moigne and Navard 2010; Lund et al. 2012). However, in the actual industrial process, in order to reduce the time spent introducing individual chemicals, all the chemicals are delivered at one stage in the chemical treatment. This leads to an excessive mixing of chemicals, and an ineffective decomposition of hydrogen peroxide and alkaline darkening, which reduces the bleaching efficiency of hydrogen peroxide. Hence, there are several major aspects still to be resolved, such as ensuring the bleaching efficiency with an appropriate alkali dosage, avoiding darkening during the alkali treatment, ensuring optimization of both the physical properties and brightness, etc.

In this study, an optimized treatment method for poplar chemi-mechanical pulp was developed, in which the wood chips were first fully impregnated with an alkali solution, and then treated with a hydrogen peroxide bleaching liquor. The processing conditions of the staged alkali and hydrogen peroxide treatment (A-P treatment) were optimized with regards to the physical properties and brightness of the chemi-mechanical pulp. Compared to the traditional alkaline hydrogen peroxide treatment (AP treatment), the optimized A-P treatment could more effectively improve the physical strength and brightness of the chemi-mechanical pulp.

\section{EXPERIMENTAL}

\section{Materials}

The poplar wood chips used in the experiments were obtained from Shan Dong Sun Paper Industry Joint Stock Co., Ltd. (Jining, China). Chip were selected to have a length of $20 \mathrm{~mm}$ to $25 \mathrm{~mm}$, a width of $15 \mathrm{~mm}$ to $20 \mathrm{~mm}$, and a thickness of $3 \mathrm{~mm}$ to $5 \mathrm{~mm}$. The selected chips were air dried and stored at room temperature. The chemical components were measured according to the methodology in the NREL/TP-510-42618 protocol (Sluiter et al. 2012), and the results are shown in Table 1. 
Table 1. Chemical Components of the Poplar Wood Chips

\begin{tabular}{|c|c|c|c|c|c|c|}
\hline $\begin{array}{c}\text { Arabinose } \\
(\%)\end{array}$ & $\begin{array}{c}\text { Galactose } \\
(\%)\end{array}$ & $\begin{array}{c}\text { Glucose } \\
(\%)\end{array}$ & $\begin{array}{c}\text { Xylose } \\
(\%)\end{array}$ & $\begin{array}{c}\text { Mannose } \\
(\%)\end{array}$ & $\begin{array}{c}\text { Acid-insoluble } \\
\text { Lignin (\%) }\end{array}$ & $\begin{array}{c}\text { Acid Soluble } \\
\text { Lignin (\%) }\end{array}$ \\
\hline 2.88 & 3.69 & 46.6 & 16.8 & 3.49 & 18.71 & 3.51 \\
\hline
\end{tabular}

\section{Comparison Experiment}

Various treatment methods were performed and compared in order to optimize the bleaching process utilizing poplar chemi-mechanical pulp. In summary, the chemical treatment methods in this study contained: (a) a single alkali treatment process (A); (b) a single hydrogen peroxide treatment process $(\mathrm{P})$; (c) the traditional alkaline hydrogen peroxide treatment process (AP); and (d) the staged alkali and hydrogen peroxide treatment processes (A-P), i.e., wood chips were submerged in an alkali liquor first and then washed with tap water until neutral, and subsequently, the washed chips reacted with the hydrogen peroxide (with a liquor ratio of 1:4). In addition, the chemical dosages (based on the weight percentage of the dry poplar wood chips) employed in different treatment methods were as follows: (a) A treatment, with an alkali dosage of 3\%, 4\%, 5\%, 6\%, or 7\%; (b) P treatment, with a hydrogen peroxide dosage of $4 \%, 5 \%, 6 \%$, or $7 \%$; (c) an AP treatment, with a $6 \%$ $\mathrm{H}_{2} \mathrm{O}_{2}$ solution and an alkali dosage of $3 \%, 4 \%, 5 \%, 6 \%$, or $7 \%$ and with a $6 \% \mathrm{NaOH}$ solution and a hydrogen peroxide dosage of $4 \%, 5 \%, 6 \%$, or $7 \%$; (d) A-P treatment, with the first stage alkali dosage either $3 \%, 4 \%, 5 \%, 6 \%$, or $7 \%$, the second stage hydrogen peroxide dosage at $6 \%$; or the first stage alkali dosage at $6 \%$, and the second stage hydrogen peroxide dosage either $4 \%, 5 \%, 6 \%$, or $7 \%$. The other treatment conditions used in the experiments were as follows: a temperature of $90{ }^{\circ} \mathrm{C}$, a reaction time of $60 \mathrm{~min}$, a $3 \%$ $\mathrm{Na}_{2} \mathrm{SiO}_{3}$ solution, a $0.5 \% \mathrm{MgSO}_{4}$ solution, and a $0.5 \%$ ethylene diamine tetraacetic acid (EDTA) solution. All these fixed treatment conditions were chosen according to preliminary experiments in this work, the results of previous studies, and the practical application of pulping industry that comprehensively considered the cost and efficiency. Each experiment was carried out at least in triplicates to ensure the accuracy of results.

\section{Experimental Procedure}

To maximize the effects of the alkali and/or hydrogen peroxide treatments, the whole experimental procedure was divided into three steps, which included: (1) a chemical treatment, (2) a mechanical treatment, and (3) paper sheet preparation. Step 1 was performed in a water bath, in which $100 \mathrm{~g}$ of air-dried wood chips were fully submerged into $400 \mathrm{~mL}$ of liquor solution, with various amounts of alkali, hydrogen peroxide, and tap water at $90{ }^{\circ} \mathrm{C}$. For step 2, a high consistency continuous disc mill (BR30-300C, Kumagai Riki Kogyo Co., Ltd, Tokyo, Japan) was used for the mechanical treatment. After being chemically treated, the unwashed chips were refined, which was divided into a rough grinding section and a fine grinding section. For the rough grinding section, the chips were fiberized with a refiner plate gap of $0.5 \mathrm{~mm}$. A refiner plate gap of $0.2 \mathrm{~mm}$ was used in the fine grinding section to subdivide the long fibers into short fibers and facilitate the fibrillation of the fibers. Afterward, the refined fibers were passed through a $0.2 \mathrm{~mm}$ sieve gap to obtain the accepted pulp. A prefiner (PFI) beating process (No. 658, PFI A/S Løten, Norway) was adopted with the conditions as follows: a pulp consistency of $10 \%$, a refining pressure of $3.33 \mathrm{~N} / \mathrm{mm}$, and the gap between the beating plate and the inner wall was 0.18 $\mathrm{mm}$. Following the PFI treatment, the paper sheets were prepared according to the TAPPI 
T525 om-6 (2006) standard method for the subsequent measurements of the properties of the paper.

\section{Analysis and Measurement}

All the measurements were tested at least five times to ensure that the measurements were accurate. The handsheets, with a basic weight of $70 \mathrm{~g} / \mathrm{m}^{2}$, were prepared for the subsequent measurements of their physical properties and brightness ( $e t$ al. 2011). The brightness of the handsheets was measured according to the TAPPI standard T525 om-06 (2006). The most important properties to evaluate the physical strength were the tensile strength and the tear index. The tensile strength that more likely to be correlated with fiber refining intensity was measured according to the TAPPI standard T494 om-01 (2001). The tear index that more strongly associated with fiber length was measured according to the TAPPI standard T414 om-04 (2004).

\section{RESULTS AND DISCUSSION}

\section{Bleaching Efficiency of Various Treatment Methods}

The brightness of the pulp obtained under various treatment methods is shown in Fig. 1. As shown in Fig. 1a, the brightness of the pulp treated with the A-P method was remarkably higher than the pulp treated with either the single A process or the traditional AP process. The brightness of the pulp treated using the A method increased initially with an increase in alkali dosage, but it decreased sharply when the alkali dosage was increased, which was most likely due to the darkening during the alkali treatment (He et al. 2005). Unlike the A treatment, the brightness of the pulp treated with the AP treatment was clearly higher, with a brightness of $67.8 \%$ ISO with an alkali dosage of $3 \%$.

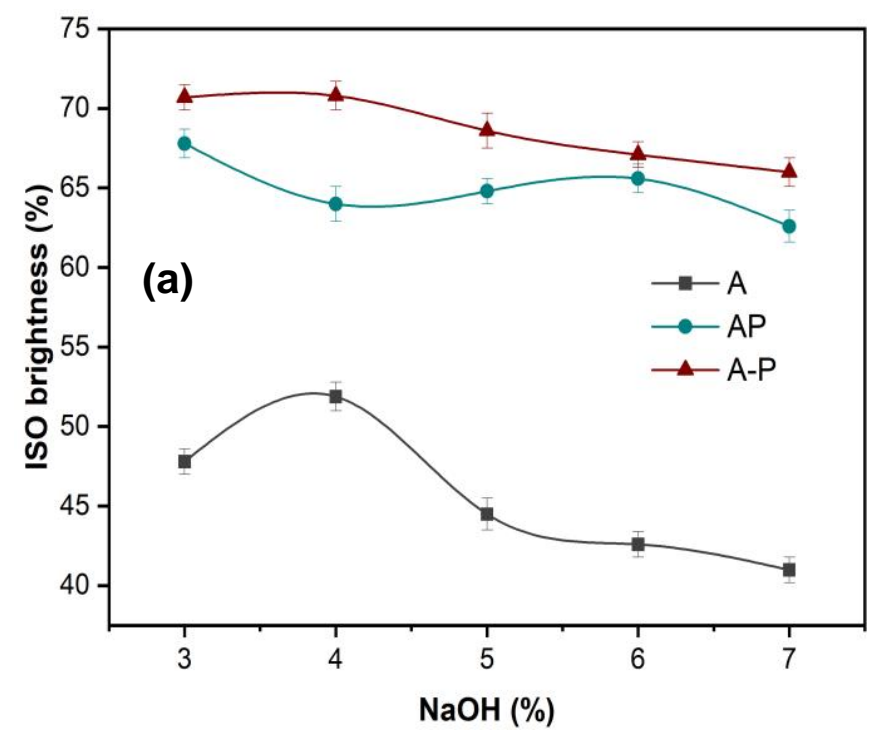




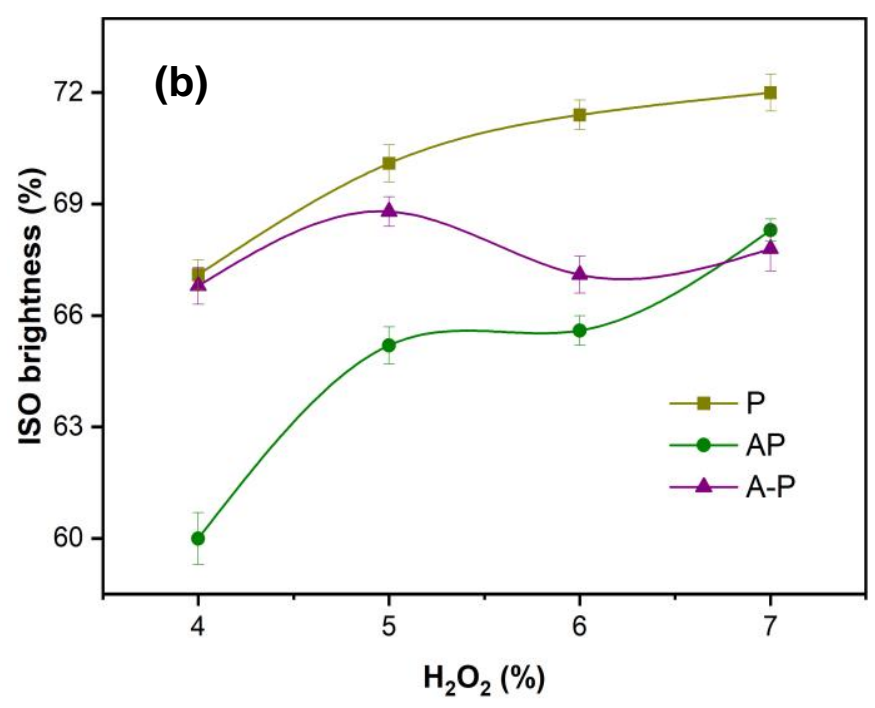

Fig. 1. Bleaching efficiency with different treatment methods under (a) different alkali dosages, the hydrogen peroxide dosage of the $\mathrm{A}, \mathrm{AP}$, and $\mathrm{A}-\mathrm{P}$ treatments were $0 \%, 6 \%$, and $6 \%$, respectively; and (b) different hydrogen peroxide dosages, the alkali dosage of $P, A P$, and A-P treatments were $0 \%, 6 \%$, and $6 \%$, respectively. The other treatment conditions were the same: a temperature of $90{ }^{\circ} \mathrm{C}$, a reaction time of $60 \mathrm{~min}$, a $3 \% \mathrm{Na}_{2} \mathrm{SiO}_{3}$ solution, a $0.5 \% \mathrm{MgSO}_{4}$ solution, and a $0.5 \%$ ethylene diamine tetraacetic acid (EDTA) solution.

For the traditional AP process, the results demonstrated that an alkali dosage of $3 \%$ was more suitable for the bleaching reaction and had the highest hydrogen peroxide bleaching efficiency; however, with a further increase in alkali dosage, the pulp brightness gradually decreased, which indicated that an excessive alkali dosage reduced the bleaching efficiency of hydrogen peroxide. The brightness of the pulp treated with the staged A-P treatment was more preferable than the pulp of other treatment methods. For example, when the alkali dosage was $3 \%$, the brightness of the pulp that underwent the A-P method treatment was $70.7 \%$ ISO, which was higher than the pulp treated with the AP method. This may be explained by the fact that after the alkali impregnation of the poplar wood chips, some extracts and lignins were removed. Therefore, the reaction area between the fiber and the bleaching solution was improved, which was conducive to the subsequent hydrogen peroxide bleaching (Song et al. 2012).

As shown in Fig. 1b, with an increase in the hydrogen peroxide dosage, the brightness of the pulp treated with the $\mathrm{P}$ method was higher than that of the pulp treated with the A-P method, while the brightness of the pulp treated with the A-P method was better than the pulp treated with the AP method. For example, when the hydrogen peroxide dosage was $6 \%$, the brightness of the pulp from the P, AP, and A-P treatments was $71.4 \%$ ISO, 65.6\% ISO, and $67.1 \%$ ISO, respectively. The brightness of the pulp from the P treatment was superior to the other treatment methods, which was most likely due to the alkali treatment leading to darkening during the alkali treatment process (Kutney and Evans 1985). It was clearly observed that the brightness of the pulp from the A-P treatment and AP treatment gradually improved with the addition of hydrogen peroxide. It was also observed that the brightness of the pulp from the A-P treatment, which had little fluctuation and remained at a high level, was higher than the AP treatment under the same chemical dosages. As demonstrated by the results, a temperature of $90{ }^{\circ} \mathrm{C}$ and an alkali dosage of $6 \%$ was the optimum technological conditions for comprehensive consideration. In summary, the brightness of the pulp from the A-P treatment was remarkably better than 
the pulp from the AP treatment, not only with various alkali dosages, but also with different hydrogen peroxide dosages.

\section{Physical Properties of Poplar Pulp after Various Treatment Methods}

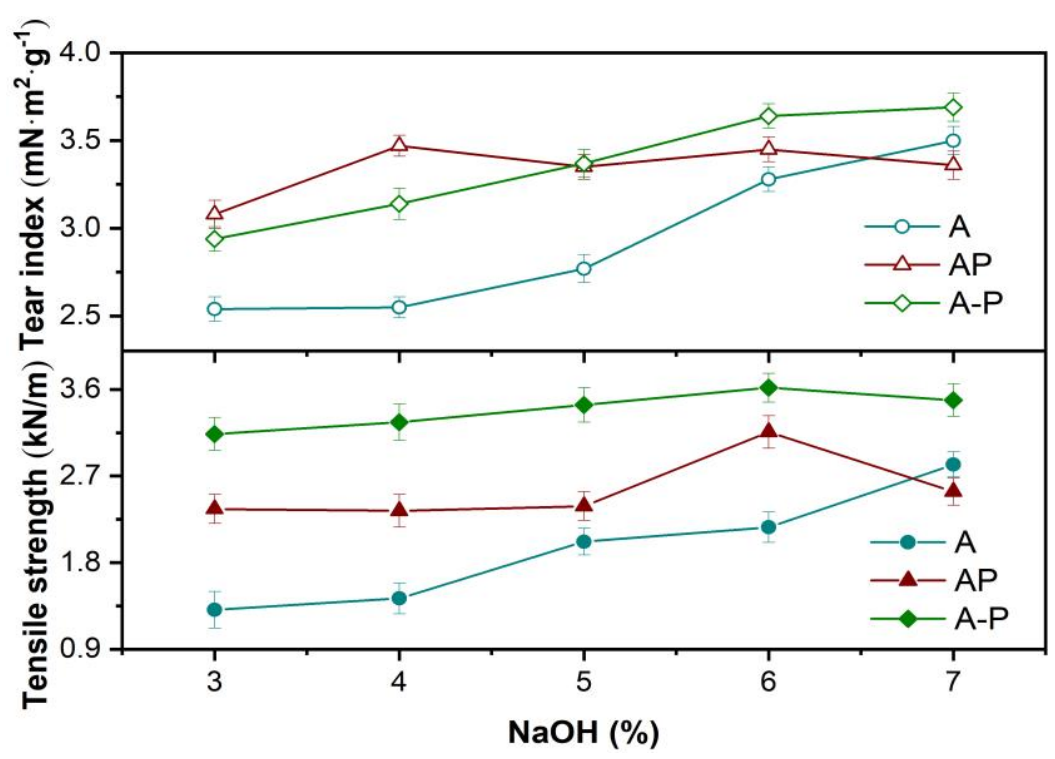

Fig. 2. Physical properties under different alkali dosages and other conditions: a $6 \% \mathrm{H}_{2} \mathrm{O}_{2}$ solution, a temperature of $90{ }^{\circ} \mathrm{C}$, a reaction time of $60 \mathrm{~min}$, a $3 \% \mathrm{Na}_{2} \mathrm{SiO}_{3}$ solution, a $0.5 \% \mathrm{MgSO}_{4}$ solution, and a $0.5 \%$ EDTA solution

Figure 2 shows the changes in the tear index and tensile strength after various alkali dosages during the A, AP, and A-P treatment methods. As shown in Fig. 2, the tear index of the chemi-mechanical pulp treated with the A treatment and the A-P treatment was improved with an increased alkali dosage. When the alkali dosage was increased from $3 \%$ to $7 \%$, the tear index of the AP treated pulp increased from $3.08 \mathrm{mN} \cdot \mathrm{m}^{2} / \mathrm{g}$ to 3.36 $\mathrm{mN} \bullet \mathrm{m}^{2} / \mathrm{g}$, which showed a lower growth rate. This was attributed to the fact that the alkali dosage for the AP treatment was excessive, and the degree of damage to the fibers was enhanced by the superposition of the alkali and hydrogen peroxide. It was observed that the tear index of the A-P treated chemi-mechanical pulp surpassed the AP treated pulp when the alkali dosage was greater than 5\%. Furthermore, when the alkali dosage was higher than 5\%, the tear index of the A-P treated pulp increased demonstrably with a further increase in alkali dosage, which was much greater than the pulp of other treatment methods, especially the tear index at a $7 \%$ alkali dosage $\left(3.69 \mathrm{mN} \bullet \mathrm{m}^{2} / \mathrm{g}\right)$. Moreover, as the alkali dosage increased, the tensile strength of the A-P treated pulp was notably greater than the AP treated pulp, while the tensile strength of the AP treated pulp was greater than the A treated pulp. In addition, when the alkali dosage was $6 \%$, the tensile strength of the A-P treated pulp was $3.64 \mathrm{kN} / \mathrm{m}$, which was preferable over the pulp from other treatment methods. Consequently, by combining the tear index and the tensile strength results from different alkali dosages, it was observed that the physical strength properties of the A-P treated pulp was obviously better than the pulp from other treatment methods. 


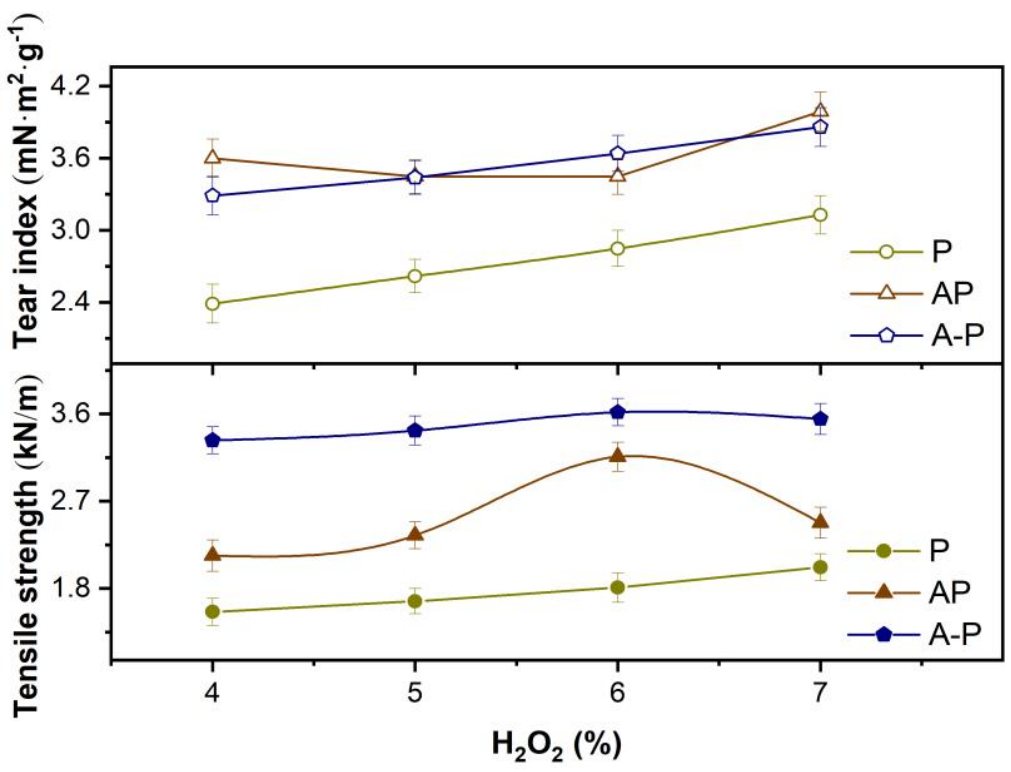

Fig. 3. Physical properties under different hydrogen peroxide dosages and other conditions: a $6 \%$ $\mathrm{H}_{2} \mathrm{O}_{2}$ solution, a temperature of $90{ }^{\circ} \mathrm{C}$, a reaction time of $60 \mathrm{~min}$, a $3 \% \mathrm{Na}_{2} \mathrm{SiO}_{3}$ solution, a $0.5 \%$ $\mathrm{MgSO}_{4}$ solution, and a $0.5 \%$ EDTA solution.

Figure 3 shows the physical properties after various treatments with different hydrogen peroxide dosages. As shown in Fig. 3, the tear index of pulp after an A-P treatment and a $\mathrm{P}$ treatment linearly increased with an increase in hydrogen peroxide dosage, while the tear index of pulp after an AP treatment showed a large fluctuation. Moreover, the tear index of A-P treated pulp was greater than the other treatment methods, and when the hydrogen peroxide dosage was $6 \%$, the tear index of A-P and AP treated pulps were $3.64 \mathrm{mN} \bullet \mathrm{m}^{2} / \mathrm{g}$ and $3.45 \mathrm{mN} \bullet \mathrm{m}^{2} / \mathrm{g}$, respectively. In addition, when the hydrogen peroxide dosage was less than $6 \%$, the tensile strength of the A-P, AP, and P treated chemimechanical pulp improved as the hydrogen peroxide dosage increased. Among them, the tensile strength of the A-P treated pulp was more preferable over the other treatment methods. For example, when the hydrogen peroxide dosage was $6 \%$, the tensile strength of the A-P and AP treated pulps were $3.62 \mathrm{mN} \cdot \mathrm{m}^{2} / \mathrm{g}$ and $3.16 \mathrm{mN} \cdot \mathrm{m}^{2} / \mathrm{g}$, respectively. Therefore, the tensile strength of the A-P treated chemi-mechanical pulp was higher than the AP treated pulp. This was thought to occur because the wood chips swelled after the alkali treatment, which likely increased porosity, thus improving the bleaching efficiency of the wood chips with hydrogen peroxide and the bonding strength of the handsheets (Kong et al. 2005). Compared to the traditional treatment methods, the physical strength of A-P treated pulp was remarkably better than the AP treated pulp.

\section{Comparison of the A-P Treatment and the Traditional Two-stage Treatment Methods}

The physical properties and brightness of the mechanical pulps treated via the staged A-P method and the traditional two-stage method were investigated, and the results are shown in Table 2. A traditional two-stage treatment method meant that in at least one of the stages the chemicals $\left(\mathrm{NaOH}\right.$ and $\left.\mathrm{H}_{2} \mathrm{O}_{2}\right)$ was delivered simultaneously at each stage. Runs 1 through 3 maintained the same amount of hydrogen peroxide, however they employed different alkali dosages. As shown in Table 2, when the treatment conditions were A 3/3 and P 0/6 (Run 2, first stage $\mathrm{NaOH} \mathrm{3 \%} \mathrm{/} \mathrm{H}_{2} \mathrm{O}_{2} 0 \%$; second stage $\mathrm{NaOH} \mathrm{3 \%} \mathrm{/}$ 
$\mathrm{H}_{2} \mathrm{O}_{2} 6 \%$ ), the tear index was $3.54 \mathrm{mN} \bullet \mathrm{m}^{2} / \mathrm{g}$, the tensile strength was $3.61 \mathrm{kN} / \mathrm{m}$, and the pulp brightness was $67.5 \%$ ISO. Runs 4 through 6 maintained the same alkali dosage while using various hydrogen peroxide dosages during the two stages. When the treatment conditions were A $3 / 3$ and P 2/4 (Run 4), the tear index was $3.35 \mathrm{mN} \bullet \mathrm{m}^{2} / \mathrm{g}$, the tensile strength was $3.75 \mathrm{kN} / \mathrm{m}$, and the pulp brightness was $69.3 \%$ ISO. In contrast, when the pulp was treated with the new staged A-P method with a first stage alkali dosage of $6 \%$ (without $\mathrm{H}_{2} \mathrm{O}_{2}$ ), and then a second stage $6 \%$ hydrogen peroxide dosage (without $\mathrm{NaOH}$ ), the tear index was $3.64 \mathrm{mN} \bullet \mathrm{m}^{2} / \mathrm{g}$, the tensile strength was $3.62 \mathrm{kN} / \mathrm{m}$, and the pulp brightness was $67.1 \%$ ISO (Run 7). Therefore, the physical properties and brightness of the staged A-P treatment pulp were superior to those of the other treatment methods.

Table 2. Physical Properties of the A-P Treated Pulp and Traditional Two-stage Alkaline Hydrogen Peroxide Treated Pulp

\begin{tabular}{|c|c|c|c|c|c|}
\hline Run Number & $\mathrm{NaOH}(\%)$ & $\mathrm{H}_{2} \mathrm{O}_{2}(\%)$ & $\begin{array}{l}\text { Tear Index } \\
\left(\mathrm{mN} \cdot \mathrm{m}^{2} \cdot \mathrm{g}^{-1}\right)\end{array}$ & $\begin{array}{l}\text { Tensile Strength } \\
\left(\mathrm{kN} \cdot \mathrm{m}^{-1}\right)\end{array}$ & $\begin{array}{c}\text { Brightness } \\
\text { (\% ISO) }\end{array}$ \\
\hline 1 & $2 / 4$ & \multirow{3}{*}{$0 / 6$} & $3.03 \pm 0.13$ & $3.12 \pm 0.12$ & $66.1 \pm 0.4$ \\
\hline 2 & $3 / 3$ & & $3.54 \pm 0.12$ & $3.61 \pm 0.1$ & $67.5 \pm 0.6$ \\
\hline 3 & $4 / 2$ & & $3.34 \pm 0.1$ & $3.17 \pm 0.14$ & $68.4 \pm 0.7$ \\
\hline 4 & \multirow{3}{*}{$3 / 3$} & $2 / 4$ & $3.35 \pm 0.13$ & $3.75 \pm 0.12$ & $69.3 \pm 0.5$ \\
\hline 5 & & $3 / 3$ & $3.24 \pm 0.15$ & $3.66 \pm 0.15$ & $65 \pm 0.6$ \\
\hline 6 & & $4 / 2$ & $3.04 \pm 0.16$ & $3.48 \pm 0.13$ & $64.6 \pm 0.5$ \\
\hline 7 & $6 / 0$ & $0 / 6$ & $3.64 \pm 0.13$ & $3.62 \pm 0.12$ & $67.1 \pm 0.7$ \\
\hline
\end{tabular}

* The other treatment conditions were as follows: a $6 \% \mathrm{H}_{2} \mathrm{O}_{2}$ solution, a temperature of $90{ }^{\circ} \mathrm{C}$, a reaction time of $60 \mathrm{~min}$, a $3 \% \mathrm{Na}_{2} \mathrm{SiO}_{3}$ solution, a $0.5 \% \mathrm{MgSO}_{4}$ solution, and a $0.5 \%$ EDTA solution

\section{Fiber Morphology}

The fiber morphologies of the poplar chemi-mechanical pulp from different treatments are shown in Figs. 4 and 5. The different magnifications of the pulp fiber after a $6 \% \mathrm{NaOH}$ treatment (A6) are clearly shown in Figs. 4a and 5a. During the A treatment, the pulp fibers were severely fibrillated, which may be due to the fact that the alkali treatment was highly effective in causing swelling of the fibers, thus reducing the damage to the fibers during the mechanical pulping process (Choi et al. 2016). During the refining process, the primary and secondary walls were deformed and stripped due to strong external forces, which resulted in the appearance of more fine fiber components (Banavath et al. 2011). 

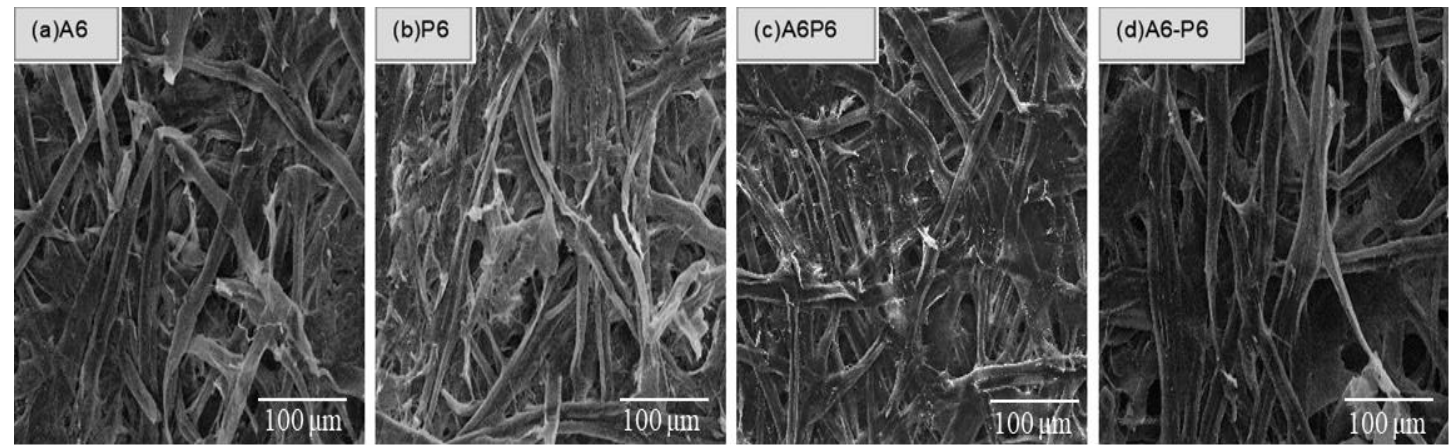

Fig. 4. Scanning electron micrographs of: (a) $\mathrm{A} 6\left(6 \% \mathrm{NaOH}\right.$ treatment); (b) $\mathrm{P} 6\left(6 \% \mathrm{H}_{2} \mathrm{O}_{2}\right.$ treatment); (c) A6P6 (6\% NaOH and $6 \% \mathrm{H}_{2} \mathrm{O}_{2}$ treatment); and (d) A6-P6 (first stage was $6 \%$ $\mathrm{NaOH}$ and second stage was $6 \% \mathrm{H}_{2} \mathrm{O}_{2}$ treatment). All pictures were taken under $500 \mathrm{X}$ magnification. The other treatment conditions were as follows: a $6 \% \mathrm{H}_{2} \mathrm{O}_{2}$ solution, a temperature of $90{ }^{\circ} \mathrm{C}$, a reaction time of $60 \mathrm{~min}$, a $3 \% \mathrm{Na}_{2} \mathrm{SiO}_{3}$ solution, a $0.5 \% \mathrm{MgSO}_{4}$ solution, and a $0.5 \%$ EDTA solution.
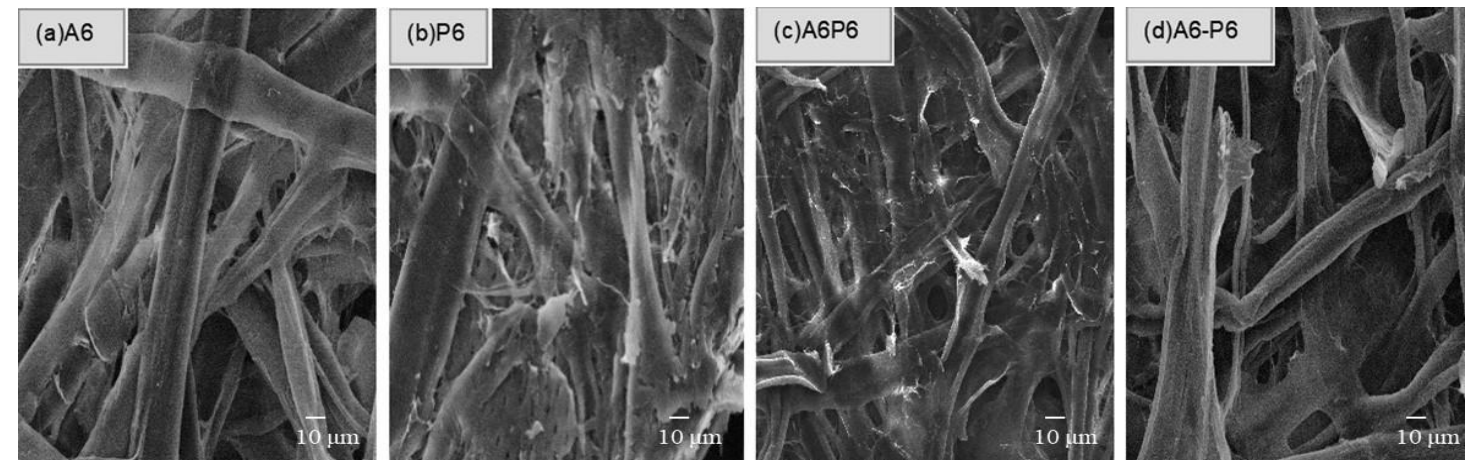

Fig. 5. Scanning electron micrographs of: (a) A6, (b) P6, (c) A6P6, and (d) A6-P6. All pictures were taken under $1000 \mathrm{X}$ magnification.

Figures $4 \mathrm{~b}$ and $5 \mathrm{~b}$ show the fiber morphologies after a $6 \% \mathrm{H}_{2} \mathrm{O}_{2}$ treatment (P6). Compared with the pulp fibers in Fig. 5a, the pulp fibers in Fig. 5b were distributed in a disorderly manner. There were obvious signs of fiber breakage due to an excessive extrusion and grinding intensity, and the fragments and faults of the fibers were visible. As shown in Fig. 4c and Fig. 5c, the fibers after a $6 \% \mathrm{NaOH}$ and $6 \% \mathrm{H}_{2} \mathrm{O}_{2}$ treatment (A6P6), the surface of the handsheets were smoother than the handsheets treated by the $\mathrm{A}$ and $\mathrm{P}$ methods; moreover, the fibers were evenly distributed and closely interwoven. Figure 4d and Fig. 5d displays the fiber morphologies of pulp treated with a first stage of $6 \% \mathrm{NaOH}$ and a second stage of $6 \% \mathrm{H}_{2} \mathrm{O}_{2}$ (A6-P6), which did not obviously display any fibrillation on the fiber surface. This may be due to the fact the fine fiber content increased after the alkali swelling, and the hydrogen peroxide bleaching reacted with the fine fibers, which resulted in the decrease of the composition of the fine fibers. Overall, the fiber fragments and fine fiber content were less, the interweaving distribution of the fibers was more uniform, and the distribution of the long fibers was obviously smooth in Fig. 5d.

\section{CONCLUSIONS}

1. A new staged alkali and hydrogen peroxide (A-P) treatment method was adopted to 
improve the physical properties and brightness of poplar chemi-mechanical pulp. The results showed that the brightness of the A-P treated pulp was much higher than the traditional alkaline hydrogen peroxide (AP) method, not only with various alkali dosages but also with different hydrogen peroxide dosages.

2. The tear index and tensile strength of the A-P treated pulp was remarkably higher than the other treatment methods. The optimized conditions for the A-P treatment method were an alkali dosage of $6 \%$ in the first stage and a hydrogen peroxide dosage of $6 \%$ in second stage; which yielded a pulp with a tensile strength and tear index of $3.64 \mathrm{kN} / \mathrm{m}$ and $3.62 \mathrm{mN} \bullet \mathrm{m}^{2} / \mathrm{g}$, respectively.

\section{ACKNOWLEDGEMENTS}

The authors express thanks for the support from the National Key R\&D Program of China (2017YFB0307900), the National Natural Science Foundation of China (Grant No. 31670590, 31870566, 31670595), the Shandong Key Research and Development Program (2018YFJH0401, 2018GGX108001), and the Taishan Scholars Program.

\section{REFERENCES CITED}

Bajpai, P. (2012). Environmentally Benign Approaches for Pulp Bleaching, ${ }^{\text {nd }}$ Ed., Elsevier, Amsterdam. DOI:10.1016/B978-0-444-59421-1.00009-0

Banavath, H. N., Bhardwaj, N. K., and Ray, A. K. (2011). "A comparative study of the effect of refining on charge of various pulps," Bioresource Technology 102(6), 45444551. DOI: 10.1016/j.biortech.2010.12.109

Barimani, A., Gholamnezhad, M., and Ghasemian, A. (2014). "The effect of using willow wood on the optical and mechanical properties of newsprint paper obtained from chemi-mechanical pulp," Journal of the Indian Academy of Wood Science 11(2), 150-155. DOI: 10.1007/s13196-014-0132-0

Chang, C.-H., Yu, S.-T., and Perng, Y.-S. (2018). "Effects of furnish and refining on properties of household paper," Cellulose Chemistry and Technology 52(5-6), 433440.

Choi, K.-H., Kim, A. R., and Cho, B.-U. (2016). "Effects of alkali swelling and beating treatments on properties of kraft pulp fibers," BioResources 11(2), 3769-3782. DOI: 10.15376/biores.11.2.3769-3782

Cuissinat, C., Navard, P., and Heinze, T. (2008). "Cellulose derivatives fibres in aqueous systems and ionic liquids: Part V," Cellulose 15(1), 75-80. DOI: 10.1007/s10570007-9159-3

El Shafie, A., Fouda, M. M. G., and Hashem, M. (2009). "One-step process for bioscouring and peracetic acid bleaching of cotton fabric," Carbohydrate Polymers 78(2), 302-308. DOI: 10.1016/j.carbpol.2009.04.002

He, Z., Ni, Y., and Zhang, E. (2005). "Alkaline darkening and its relationship to peroxide bleaching of mechanical pulp," Journal of Wood Chemistry and Technology 24(1), 112. DOI: $10.1081 / \mathrm{WCT}-120035940$

Huang, C., Chen, Y., Zhao, Y., Xue, D., Li, C., and Zhu, M. (2017). "Physical strength improvement of eucalyptus alkaline hydrogen peroxide mechanical pulp by low- 
temperature plasma treatment," BioResources 12(4), 9075-9085. DOI:

10.15376/biores.12.4.9075-9085

Istek, A., and Gonteki, E. (2009). "Utilization of sodium borohydride $\left(\mathrm{NaBH}_{4}\right)$ in kraft pulping process," Journal of Environmental Biology 30(6), 951-953.

Jurd, L. (1964). "Reactions involved in sulfite bleaching of anthocyanins," Journal of Food Science 29(1), 16-19. DOI: 10.1111/j.1365-2621. 1964.tb01685.x

Khakifirooz, A., Ravanbakhsh, F., Samariha, A., and Kiaei, M. (2013). "Investigating the possibility of chemi-mechanical pulping of bagasse," BioResources 8(1), 21-30. DOI: 10.15376/biores.8.1.21-30

Kong, F., Chen, J., Wang, S., and Zhan, H. (2005). "Effect of $\mathrm{NaOH}$ charge on fiber characteristics of P-RC APMP pulp," in: Incorporating the $13^{\text {th }}$ ISWFPC (International Symposium on Wood, Fibre and Pulping Chemistry), Auckland, New Zealand, pp. 16-19.

Kutney, G., and Evans, T. D. (1985). "Peroxide bleaching of mechanical pulps - Part 2 Alkali darkening - hydrogen peroxide decomposition [colour reversion]," Svensk Papperstidning 88(9), 84-89.

Lei, M., Zhang, H.-J., Li, J.-G., and Duan, J.-L. (2013). "Characteristics of poplar preconditioning followed by refining chemical treatment alkaline peroxide mechanical pulp fiber fractions and their effects on formation and properties of highyield pulp containing paper," Industrial and Engineering Chemistry Research 52(11), 4083-4088. DOI: 10.1021/ie3024356

Lund, K., Sjöström, K., and Brelid, H. (2012). "Alkali extraction of kraft pulp fibers: Influence on fiber and fluff pulp properties," Journal of Engineered Fibers and Fabrics 7(2), 30-39. DOI: 10.1177/155892501200700206

Le Moigne, N., and Navard, P. (2010). "Dissolution mechanisms of wood cellulose fibres in NaOH-water," Cellulose 17(1), 31-45. DOI: 10.1007/s10570-009-9370-5

Narvestad, H., Gregersen, O. W., and Kure, K.-A. (2013). "Effect of sodium dithionite post-bleaching on the clay-induced discolouration of a hydrogen peroxide bleached mechanical pulp," Nordic Pulp and Paper Research Journal 28(3), 342-348. DOI: 10.3183/npprj-2013-28-03-p342-348

Nguyen, X. T. (2011). "Process for non-chlorine oxidative bleaching of mechanical pulp in the presence of optical brightening agents," U. S. Patent No. 7967948.

Rainey, T. J., and Covey, G. (2016). "Pulp and paper production from sugarcane bagasse," in: Sugarcane-Based Biofuels and Bioproducts, Ian M. O'Hara and Sagadevan G. Mundree (ed.), John Wiley and Sons, Hoboken, NJ, USA, pp. 1-25. DOI: $10.1002 / 9781118719862 . c h 10$

Saberikhah, E., Rovshandeh, J. M., and Rezayati-Charani, P. (2011). “Organosolv pulping of wheat straw by glycerol," Cellulose Chemistry and Technology 45(1), 6775.

Sluiter, A., Hames, B., Ruiz, R., Scarlata, C., Sluiter, J., Templeton, D., and Crocker, D. (2012). Determination of Structural Carbohydrates and Lignin in Biomass (NREL/TP-510-42618), National Renewable Energy Laboratory, Golden, CO.

Song, X., He, H., Li, Z., Wang, Q., and Wang, S. (2012). "Dissolving behavior of carbohydrate ingredients during pre-Extraction process of alkaline hydrogen peroxide of bamboos," Journal of Testing and Evaluation 40(3), 343-348. DOI: 10.1520/JTE104494

Suess, H. U. (2009). "Bleaching," Restaurator 30(4), 245-279. DOI: 10.1515/rest.015 Suess, H. U. (2010). Pulp Bleaching Today, Walter de Gruyter, Berlin, Germany. DOI: 


$$
10.1515 / 9783110218244
$$

TAPPI T414 om-04. (2004). "Internal tearing resistance of paper (Elmendorf-type method)," TAPPI Press, Atlanta, GA.

TAPPI T494 om-01. (2001). "Tensile properties of paper and paperboard (using constant rate of elongation apparatus)," TAPPI Press, Atlanta, GA.

TAPPI T525 om-06. (2006). "Diffuse brightness of paper, paperboard and pulp (d/0)," TAPPI Press, Atlanta, GA.

Article submitted: October 11, 2019; Peer review completed: November 17, 2019;

Revised version received: December 11, 2019; Accepted: December 12, 2019; Published:

December 19, 2019.

DOI: $10.15376 /$ biores.15.1.1062-1073 